\title{
A New Perspective on the Way Forward - Case Studies in Integrated Economic and Environmental Coastal Management
}

\author{
Peter Hebard BSc,CEng, FIMechE, Realisations UK, peterh@realisations-uk.co.uk; \\ David Weight MRICS, Davis Langdon, david.weight@davislangdon.com
}

\begin{abstract}
We face an increasingly wide range of threats to our marine, coastal and estuarine environments, many aggravated by human activity. Attempts to manage these problems in isolation are looking ever more ineffective and unaffordable, and over-prescriptive regulation threatens to render many options inaccessible. However case studies around the world suggest a radically different more holistic approach. Examining all activities within a coastal zone, the needs of those that are pursuing them and the possibilities for mutually beneficial collaboration can reveal "win-win" opportunities for environmental and economic regeneration that current regulatory authorities and processes might never identify. These can often be delivered at little or no cost to the taxpayer. In many cases the primary drivers for such projects are economic but, since coastal economies are often founded on maximising the returns from their environment, there can be great benefits in an integrated approach. It is becoming clear that protection of habitat and prevention of all negative impacts, however small, may not always be the best tools to nurture our environment and that governments are rarely the best placed to deliver the required solutions. This paper explores the approach of seeking constructive contributions from all those active within a coastal locality and its adjacent marine environment with the aim of achieving a net positive environmental impact, often at little or no cost to the taxpayer, applying conventional risk management practice to mitigate negative impacts.
\end{abstract}

\section{The Project Approach}

The aims of this paper, and the case studies that have supported it, has been to examine the benefits of holistic coastal strategies, to explore what may have predicated against them in the past and to identify the best ways to realise their full potential in the future.

The authors have searched the world for best practice and proven solutions to enable them to be able to promote more positive action. They have reviewed those coastal projects around the UK, in which they played an active part in the past, and taken an interest in many more overseas. In particular, they have explored the marked contrast in the Southern Hemisphere, where a greater freedom to act has led to the development of more innovative technologies and more effective holistic solutions, better able to meet future challenges.

Case studies for the EA and DEFRA have looked at the prime objectives and the many additional benefits such strategies offered, the sources of funding and support secured to realise their full potential, and the range of technologies and innovative solutions deployed. Furthermore on some UK projects where not all opportunities have yet been realised, the authors have explored what would be needed to implement such strategies in full.

Such cases are rarely covered by previously published research from the perspective of this paper. The approach has therefore been to make contact with those who played a key part in each and, where possible, obtain independent views of several stakeholders.

To be able to broker agreement between all stakeholders and defuse any antagonism between them, - for instance, between fishermen and aggregate dredgers - it is important to identify ways they can assist each other, often at little or no cost to themselves. The authors

This is an Open Access article distributed under the terms of the Creative Commons Attribution-Noncommercial License 3.0, which permits unrestricted use, distribution, and reproduction in any noncommercial medium, provided the original work is properly cited. 
have identified the most important and have consulted academic and other expert institutions to seek solutions to the most common concerns.

They have also identified those key enabling technologies that offer multiple benefits and would merit their piloting, development and proving for repeated use.

Whereas the regulatory frameworks tend to focus on protecting certain endangered species, preserving unique habitat and fostering bio-diversity, the case studies focus on wider interpretation of positive environmental impact to include those aspects valued by local communities and their visitors and contribute to their local economy. These might include restoring the avian habitat most visible to visiting tourists from a coastal path or providing habitat for the fish species caught by local fishermen.

\section{The External Factors that Influence Coastal and Marine Management Practice}

\section{The Impact of Regulation and Single Issue Authorities}

Many recognise that is becoming increasingly ineffective and unaffordable for governments alone to seek to manage the emerging challenges to our coastlines and marine environment.

Whilst the electorate still believed government should fund such works, it was perhaps expedient in the past for them to argue that defending our coastlines is not cost effective and for their advisors to support such a case. However, mistrust of such scientists is growing and the emergence of the threats posed by sea level rise and increasing storm intensity make that approach far less tenable, as many more of the electorate now expect action.

Furthermore, with the introduction of more national and international marine legislation, many widely-employed coastal defence solutions may soon be outlawed due to their adverse impact on the marine environment, whilst the additional layers of over-prescriptive regulation currently being proposed could seriously inhibit more intelligent and pragmatic alternatives.

However perhaps the most important factor has been the narrowly defined terms of reference of the many government agencies that may have an interest in a particular locality and their overlapping and occasionally conflicting responsibilities. They are effectively disbarred from taking the lead to develop an over-arching holistic solution, let alone deliver it, particularly one that offers both environmental and economic benefits or incorporates contributions from the private sector that they would not be in a position to accept.

\section{Exploiting Economic Value for Environmental Ends}

Our coastlines represent some of the country's most valuable real estate and the ability of recreational activities such as surfing to attract the finance needed to defend it and regenerate local economies should not be under estimated. It is entirely sensible to exploit both to meet the two highest profile challenges of our decade - climate change and the world economic downturn - in an integrated strategy. .

Equally it is perhaps as important for future generations to provide the good husbandry to nurture the natural productivity of our marine environment and resources, as it is to focus solely on biodiversity. Indeed, the perception that the two approaches are mutually exclusive is perhaps misguided and the findings of this research would suggest the truth is closer to the reverse.

\section{Managing Risk in the Coastal Environment}

The "precautionary principle" has dominated environmental practice for many years, perhaps driven by the enthusiasm of the press to highlight teething troubles, magnify them out of all proportion and seek to allocate unwarranted blame. As any career-minded civil servant knows, it is not in his interest to take risks. Even if he believes it is worth trying something 
new, it is better for him to use a method that has been used many times before, if he values his future. His elected superiors and the regulators may also urge similar caution in their own best interests, as, in the event of a failure, they can all then claim that, irrespective other options, best practice had been followed.

The authors, both keen coastal observers, who have been called upon to give guidance to coastal communities and governance for coastal projects over decades, have nonetheless spent their professional careers in the engineering and construction industries, where taking calculated risks is essential to out-perform the competition and the successful exploitation of innovation and commercial potential are the recognised measures of achievement.

As practitioners of Risk and Turnaround Management, both focused on delivering the solutions that best meet their commercial clients' needs, they are only too aware of the difference in practice and outcomes between their everyday and governance worlds. They suspect far more could be achieved in coastal management circles by adopting a policy of continuous improvement and seeking to develop new methods of coastal defence, albeit through carefully controlled trials.

Risk management focused on identifying and mitigating the most real and present risks can be very effective and much more can be learnt from such practical trials. It is entirely possible to manage these at minimal risk to the environment, as a later example shows, often at less cost and more effectively than the extensive paper studies now demanded by the regulators.

\section{Facilitating Stakeholder Engagement for Holistic Strategies}

Developing such strategies and enlisting the widest support for them is no easy task, particularly as many stakeholders - environmentalists and developers, for example - are long-standing adversaries. Such adversaries may view any third party seeking to broker some accommodation between them as unwarranted interference, unless opportunities for mutually beneficial collaboration can be quickly brought to the fore.

The first step must be to ascertain the needs and concerns of each party in isolation, together with their views on what can be done, both for them and the wider environment, and their capability and willingness to play their part.

The best means to do so is to conduct a SWOT (Strengths, Weaknesses, Opportunities and Threats) analysis but, importantly, to add an action to address each, line by line. Many of these solutions will require research, innovation, lateral thinking and reference to a wide range of experts to be credible but it is critical to identify them early. Whereas preference might usually be given to proven methods, innovative solutions that offer a wider range of side benefits may be more important to achieving the maximum net positive impact.

Frequently it emerges that the same action can offer more than one benefit for a range of stakeholders, providing powerful justification for an action plan that might have previously seemed unaffordable - creating habitats for fish catches might not be affordable but if it were to be provided by a recreational surf reef that would regenerate the local economy, retain beach replenishment and both protect and enhance the value of major real estate, public and private finance would be fully justified.

\section{Technologies to Deliver Stakeholder Engagement and Win-Win Solutions}

\section{Harnessing Natural Processes}

Both "hard" and "soft" engineering are becoming increasingly unacceptable but by harnessing natural processes and permitted human activities, it can prove possible to achieve what is needed in a relatively benign and carbon-efficient way. Change can often be 
achieved merely by minor modifications to existing permitted activities, avoiding the need to seek environmental approval or to call on the taxpayer, and often wider spin-off benefits can enlist the support of other stakeholders and the local community.

To do so it is important to understand the individual cyclical natural processes, those that can be re-directed to move sediment to where it is needed.

For example, individual waves can move sediment up, down and along beaches. It is well known that, in simple terms, large waves and those at an oblique angle pull sediment down beaches; small waves, at right angles to it, move it up a beach. Using a sub-surface wavebreak or reef to refract prevailing waves towards the shore and cause large waves to break offshore, whilst allowing smaller ones to pass over and break on the beach, can reverse natural erosive processes and promote natural accretion.

England alone places $36,000,000 \mathrm{~m}^{3}$ of aggregate on our beaches annually, yet Narrowneck artificial reef on the Gold Coast in Australia has been shown to reduce the loss of beach replenishing sediment to virtually zero and created some fertile marine habitat too.

Sub-surface wave breaks may have proved successful as artificial surf reefs to regenerate coastal economies, for example in Bournemouth, but they have many other uses; restoring our coastline, creating habitat and spawning grounds, making beneficial use of dredgings or replacing rock groynes, to name a few, yet they are rarely used in the UK, as the advantages have yet to be demonstrated with sufficient confidence to ease regulatory approval.

Other processes move sediment with storms and tides. The world knows that an estuary will form a bar and/or delta at its mouth, formed by ebb tides and fluvial flows. What is less widely recognised is how that sediment can be picked up and carried back upstream by storms and flood tides. Such a reservoir of loose-lying sediment is often available within an estuary to be diverted to replenish areas being depleted or even to promote accretion in anticipation for climate change. The right retention matrix can capture and secure it.

\section{Practices of Past Generations and from Other Industries}

As an aid to the lateral thinking that is needed in stakeholder negotiations, it is useful to look back to past practice and aside to the methods used in other industries, particularly as they can highlight innovative ways to do "more with less," often far more benignly than modern carbon-intensive practices.

Mining engineers have been harnessing natural processes to do their work for them for centuries and marine aggregate dredgers exploit the natural sorting that goes on continually beneath our seas to extract precisely sized sediment that collects in particular localities. These sorting processes can be harnessed to assist in making beneficial use of dredgings.

For example dredging spoil containing aggregate but contaminated with sediment, might be placed on a shingle bank offshore from a spit in need of replenishment. It will initially enhance the natural wave-break protection to the spit and the fine sediment is likely to be carried to some more benign location, maybe to replenish a saltmarsh, whilst by the time the shingle reaches the beach to replenish it, it will be washed clean.

In another example, a small highly protected drying river in south Devon was an important transport artery in previous centuries. A study aimed at restoring the navigation channel by natural processes, highlighted that much of the sediment migrated outward on the last of the ebb and looked at a number of ways of benignly redirecting and augmenting that flow - by moving oyster sets and boat moorings, and controlling the timing of releases of water from a reservoir up stream - only to find that in the early part of the last century such practice was common place but achieved far more simply. 
The harbour master used to go out by boat on an occasional spring tide at the start of the ebb, towing a small chain harrow. He would trawl through natural braiding on the river bed to cut a small break in one location just upstream of the main quay. The ebb tide would then widen out the same break to maintain the deepest channel along the front of the quay.

\section{Redirecting Human Activities}

In respect of coastal and marine management, there are now many much more powerful activities permitted on our estuaries and offshore today. Often they are perceived as damaging but such power can often be redirected to positive effect.

For example, new much larger ferries on a coastal estuary had been perceived as unpopular by some but welcomed by others, as their propulsion units scoured the channel, obviating the need to dredge it. However the channel markers they followed were placed in last century and are 2.5 times wider apart than they needed to be. The ferries ranged over the whole width and cut a $70 \mathrm{~m}$ wide $4 \mathrm{~m}$ deep trench without reason. Furthermore they followed several pairs of leading lights on a sharp zigzag course up the river, even though they had full electronic navigation on board.

By defining the course to be followed electronically, perhaps as a more natural series of curves, ferry masters would able to follow it precisely, keeping close to the centre-line whenever possible. The area swept by their propulsion units could be reduced by more than $70 \%$, with a consequent reduction in erosion. The channel would still be as deep in the centre, if not deeper, but more room would be left for smaller boats and saltmarshes either side deprived of less sediment, reducing the need to build new inner harbour sea defences. Any increase in depth could allow in the larger yachts, important to the local marine industry.

Tests on the loose-lying sediment revealed that any dispersed in this way would not only be carried out to sea on the ebb tide and lost to the local ecosystem but also be carried up river to drop out under moorings and in marinas on the flood, areas that needed to be dredged regularly. Any reduction in dispersion should also reduce dredging costs too.

\section{Making Beneficial Use of Dredgings}

Furthermore, the dredgings from marinas up river were being dumped offshore into an area that was soon to be designated a marine conservation zone, so it would seem sensible to explore restoring the dredging sediment to the saltmarshes. The same sub-surface reef technology described previously would provide the means to do so benignly. By placing low cost bag reefs filled with dredging sediment outside the marshes, split hull dredging barges would be able to dump the spoil just in shore of them. Waves breaking over the reefs would disperse the sediment, allowing storms and tides to carry it into the saltmarshes by a benign and natural method. This would have the additional benefits of protecting the saltmarsh and a recently exposed sea wall from further erosion.

The restoration of the saltmarsh avian habitat within sight of a popular coastal path along this seawall would prove attractive to bird lovers and bring in additional tourist revenue whilst spreading the cost of additional coastal protection measures that might otherwise soon be needed over many more years to come. 


\section{Fostering More Productive Habitat for Local Fisheries}

The bag reef woul provide spawning habit for local fish catches and seeding ground could be created on its seaward side for local oysters. Retaining the sediment within its own ecosystem would reduce the amount that might otherwise contaminate oyster and other shellfish beds near the original dumping ground, further improving marine productivity offshore for shellfisheries operating from the harbour.

\section{A Holistic Win-Win Strategy for All at No Cost to the Taxpayer}

Thus from a simple strategy to make best use of the power of a new ferry and defuse local antagonism, to it, a total of fifteen side benefits could be secured. It only required a slight redirection of the two already licensed activities, a ferry operation and dredging and both operators would actually save cost by doing so. It would offer major gains to the environment, addressing the aspects valued by the local community, namely avian habitat and coastal defence, rather than species specifically protected by habitat regulations but habitats and biodiversity would benefit too.

A review of estuaries, harbours and coastal communities known to the authors around the Solent and SW coast, studying their needs, local concerns and ongoing activities has revealed that every one would derive similar economic and environmental benefits from such a holistic local strategy, and surprisingly few would need to call on the taxpayer for additional funds.

\section{The Way Forward}

\section{De-Risking the Technologies}

As mentioned earlier, mechanical engineers are well used to developing new technologies by monitoring small scale stage by stage prototypes and conducting pilot trials, refining the design along the way. It is second nature to control and confine risk to well within acceptable levels.

Using a bag reef to aid return of dredging spoil to the saltmarsh is a useful example. The environmental risk of placing one bag in an area of recently eroded saltmarsh and one dredger-load of sediment behind it is negligible but much can be learnt from monitoring the result, which can be used to inform an application for full scale trial of, say, 10 times the size. Should this be successful then ongoing approval for all dredgings to be disposed of in this way should be a formality, after an adequate monitoring process. At any time process could be aborted and the bag reef removed simply by cutting it up and allowing the dredgings to return to the same ecosystem from whence they came.

Rather than taxpayers funding such research in full, just providing regulatory flexibility might provide the catalyst. Demonstration sites can be found around the UK to prove most emerging technologies by such methods, many funded and/or enabled by local stakeholders. Most have already been proven around the world, principally in the southern hemisphere.

\section{Solutions that Would Merit Demonstration and Proving}

Reviewing the many projects within the case studies and their wider experience, the authors have identified certain key applications of innovative technologies and in many cases suitable locations for such trials. It is hoped that regulatory agencies will encourage and facilitate such trials. They and others can thereby gain confidence in a wider range of techniques that could collectively offer highly positive benefits for our marine and coastal environment and major reductions in their own costs of protecting our coastline too. 
In particular, sub-surface wave-breaks can provide solutions for a wide range of applications including:-

1. Protecting and promoting re-accretion of saltmarsh and beaches

2. Beneficial use of dredgings for saltmarshes and replenishing shingle systems

3. Preventing loss of beach replenishment to reduce demand

4. As an alternative to rock groynes and offshore breakwaters

5. Providing recreation through surfing/wind surfing and aiding economic regeneration

6. Creating habitat \& spawning grounds for local fish catches and nurturing biodiversity

To prove all the above applications would only require a programme of three successive pilot trials, most of which would be self-funding or incur minimal cost but would offer immediate potential to deliver major savings. The saltmarsh trial replenishment trial above would also de-risk the use of sub-surface reefs for promoting re-accretion of saltmarsh and preventing erosion, to replace groynes and retain beach replenishing sediment, sufficient to make FEPA licensing and associated EIAs less demanding. This would then clear the way for trials of larger offshore reefs for retaining beach replenishment and protecting much larger structures.

It is important to have solutions that allay the concerns of stakeholders and to maximise our marine resources. The most pressing example is for fishermen and shell fisheries, who often rightly fear the consequences of every new marine activity. All others need to know methods to create productive habitat to allay their concerns. One well proven solution is to recycle tyres for the purpose as, apart from an early unfortunate mis-application in Florida, they have been shown to be highly beneficial and need not be classified as waste, if used in high integrity structures. These can be used to:-

- leave aggregate dredging zones more productive than prior to extraction

- create productive habitat and prevent scour in wind farm exclusion zones

- add a habitat-creating additional constituent to offshore reefs

\section{Conclusions}

To summarise the findings of this paper and related research, it is important to ensure that the approach to Holistic Coastal Management-

- is unfettered by narrow sectoral responsibilities and terms of reference.

- seeks to achieve "net positive environmental impact" rather than the "no negative impact" of current regulations

- applies risk management focused on mitigating major risks rather than the allembracing "precautionary principle" that tends to obstruct innovation

- exploits the enthusiasm of major enterprise and responsible citizens to demonstrate "green" credentials by offering project finance or other assistance

- offers economic and other side benefits to stakeholders to enlist their collaboration and reduce or eliminate the need for funding from the taxpayer

- addresses the full range of local priorities to ensure the widest popular support

- seeks to regenerate the local economy, whilst nurturing marine resources and the natural environment 
Innovative solutions are required to:-

- harness natural processes to do what is needed

- redirect permitted activities to achieve a positive impact

- consider the marine, coastal and hinterland zone as a single entity

- look for positive contributions from all parties, rewarded by equally positive benefits from collaboration/cooperation

REFERENCE PROJECTS (Subjects of case studies that are the foundation of this paper)

Boscombe Surf Reef - Bournemouth - Project funded by developers and Borough Council, justified by increase in waterfront property values and need to retain beach replenishment.

Borth Surf Reef - Wales -.Coastal protection, amenity \& ecological enhancement jointly funded by the Welsh Assembly and EU Regional Development Fund.

Bournemouth/Swanage Beach Replenishment - Making beneficial use of Poole Harbour entrance dredgings funded by Harbour Commissioners, Borough and District Councils.

Lymington Options for Change \&Waterfront Strategy - Projects supported by DEFRA, SE England Development Agency the Community Forum and local Councils.

Solent Waterfront Towns and Coastline Protection - a range of projects at various stages of completion but worthy of study, particularly in view of their interconnected nature;

- Beaulieu - Shoreline defence supported by local landowners.

- Bembridge - Sea wall restoration, flood prevention and environmental enhancement.

- Cowes breakwater - funded jointly by SEEDA, Harbour Authority and developers.

- East Head - Beach reinforcement funded Harbour Authority, Community and Council.

- Selsey Bill - beach reinforcement to protect caravan park funded by site owners.

- Southampton Water Capital and Maintenance Dredging secondary uses of spoil.

Avon Estuary Siltation Research Project - S Devon - a project supported by local benefactors to harness estuarine processes to reverse siltation in a ANOB/SSSI.

Isle of Man Scallop Fisheries - Creation of spawning habitat using marine cable and artificial reef created by cable laying contractor.

Venice - Restoration of the Venetian lagoon saltmarshes using channel dredgings and harnessing natural processes to carry in sediment.

Narrowneck Reef - Gold Coast Australia to retain beach nourishment material and protect threatened shoreline justified through benefits of beach works on Tourism revenue.

St Francis Bay - South Africa - Coastal protection/amenity enhancement/ecological enhancement funded by levies on increased property values.

Wells Estate - South Africa - Coastal protection/amenity enhancement/ecological enhancement funded partly increase in land values and partly by the municipality. 
Mount Reef - New Zealand (cat iii) coastal protection/amenity enhancement/ecological enhancement funded by a partnership between a Charitable Trust and the Council.

Taranaki - New Zealand - Dredging spoil placement for coastal defence funded by local council and private organisation.

\section{ACKNOWLEDGMENTS}

Thanks to all those associated with the above projects and the development of the innovative coastal protection and habitat creation technologies mentioned, in particular those at the National Oceanography Centre, Southampton, Plymouth Marine Laboratories and ASR Ltd, $\mathrm{NZ}$ that contributed the understanding and perception that is the foundation of this paper. 